\title{
Inhibition effect of flavophospholipol on conjugative transfer of the extended-spectrum $\beta$-lactamase and vanA genes
}

\author{
Hayami Kudo ${ }^{1,2} \cdot$ Masaru Usui ${ }^{1} \cdot$ Wataru Nagafuji ${ }^{1} \cdot K^{2}$ taro Oka $^{2} \cdot$ Motomichi Takahashi $^{2} \cdot$ Hiroyuki Yamaguchi $^{3} \cdot$ \\ Yutaka Tamura ${ }^{1}$
}

Received: 21 June 2018 / Revised: 2 October 2018 / Accepted: 8 October 2018 / Published online: 25 October 2018

(c) The Author(s) 2018. This article is published with open access

\begin{abstract}
Flavophospholipol (FPL) is an antimicrobial feed additive that has been approved for use in livestock animals and has the potential to decrease horizontal dissemination of antimicrobial resistance genes. Since previous studies showed that FPL has an inhibitory effect on plasmid transfer, in vitro experiments have proven the efficacy of FPL in reducing the conjugative transfer of plasmids encoding the extended-spectrum $\beta$-lactamase (ESBL) and vanA genes. These are among the most important antimicrobial resistance loci known. ESBL-producing Escherichia coli and vancomycin-resistant Enterococcus faecalis (VRE) were exposed to several concentrations of FPL, and transfer frequency and plasmid curing activity were determined. FPL inhibited the conjugative transfer of plasmids harboring ESBL and vanA genes in a concentrationdependent manner in all strains. Further transfer experiments revealed that FPL could decrease or increase transfer frequency depending on plasmid type when transfer frequency was at low levels. The plasmid curing activity of FPL was also observed in ESBL-producing $E$. coli in a concentration-dependent manner, suggesting that they partially contribute to the inhibition of conjugative transfer. These results suggest that the use of FPL as a feed additive might decrease the dissemination of ESBL and vanA genes among livestock animals.
\end{abstract}

\section{Introduction}

Antimicrobials are used in livestock animals to treat bacterial infection. In addition, some antimicrobials are used as feed additives to improve the quality of products and promote growth [1]. However, inappropriate use of antimicrobials can provide an opportunity for antimicrobial resistance, which may spread between livestock animals

Masaru Usui

usuima@rakuno.ac.jp

Yutaka Tamura

tamuray@rakuno.ac.jp

1 Laboratory of Food Microbiology and Food Safety, Department of Health and Environmental Sciences, School of Veterinary Medicine, Rakuno Gakuen University, Ebetsu, Hokkaido 0698501, Japan

2 Tokyo R\&D Center, Miyarisan Pharmaceutical Co., Ltd., Saitamashi, Saitama 331-0804, Japan

3 Department of Medical Laboratory Science, Faculty of Health Sciences, Hokkaido University Graduate School of Health Sciences, Sapporo, Hokkaido 060-0812, Japan and humans via food chains or through the environment, increasing the risk of severe infections [2]. Some antimicrobial resistance genes are carried on plasmids and the ease of conjugative transfer of those plasmids allows rapid spread of antimicrobial resistance [3].

The extended-spectrum $\beta$-lactamase genes (ESBLs) and some vancomycin (VCM) resistance genes, such as vanA and $\operatorname{van} B$, are carried on plasmids and are some of the most intensely researched antimicrobial resistance genes in the world. The plasmid-mediated ESBL genes, which can confer resistance to third-generation cephalosporins, have been observed in isolates derived from livestock animals [4-7]. The third-generation cephalosporins are clinically important antimicrobials due to their little reported side effects and broad-spectrum activity [6]. The vanA gene cluster is located on $\mathrm{Tn} 1546$, which often resides on a plasmid in vancomycin-resistant enterococci (VRE) [8]. VRE possess a high-level resistance to VCM. Moreover, most VRE are resistant to both $\beta$-lactam and aminoglycoside antibiotics [8]. VCM is also clinically important as it is recommended for the treatment of infections caused by Clostridium difficile and MRSA [9, 10]. Concerningly, the persistence of VRE carrying the vanA gene was observed in 
livestock animals 10 years or more after avoparcin (related to VCM) was banned in some European countries [11, 12]. Thus, efficient countermeasures to prevent the spread and maintenance of plasmid-mediated ESBL and vanA genes among livestock animals are required.

Flavophospholipol (FPL), also known as flavomycin, moenomycin, and bambermycin, is an antimicrobial that is produced by Streptomyces spp. and used as a feed additive for poultry and piglets in some countries including Japan, but its use is limited in the EU [1]. It is reported that FPL inhibits glycosyltransferase, an enzyme involved in cell wall synthesis. In addition to this mode of action, FPL has showed an inhibitory effect on plasmid transfer [13, 14]. In our knowledge, few studies have tested the inhibitory effect of FPL on a wide range of plasmids belonging to different incompatibility groups. To clarify the inhibitory effect of FPL on conjugational transfer of ESBL and vanA genes, we exposed ESBL-producing E. coli and VRE, which contains several types of plasmids, to FPL, and determined transfer frequency and plasmid curing activity.

\section{Materials and methods}

\section{Strains}

To determine the inhibitory effect of FPL on conjugative transfer of highly transmissible plasmids, we selected strains for experiments of conjugative transfer with FPL. In the first round transfer experiment, three donor strains of ESBL-producing E. coli previously isolated from bovine feces at Rakuno Gakuen University: Dc1 (133), Dc2 (TC13-1), and Dc3 (TC7-1), were used [15, 16]. Dc1, Dc2, and Dc3 contain self-transmissible plasmids carrying the $\beta$ lactamase genes (bla $a_{\mathrm{CTX}-\mathrm{M}-15}, b l a_{\mathrm{CTX}-\mathrm{M}-14}$, and $b l a_{\mathrm{CTX}-\mathrm{M}-2}$, respectively). All these donor strains were resistant to ampicillin (ABPC), cefazolin (CEZ), and cefpodoxime (CPDX). The incompatibility groups of the $\beta$-lactamase gene encoding plasmids of three donor strains are FIB, I1I $\gamma$, and N, respectively. E. coli ML4909 (Rc), a rifampicin (RIF) -resistant derivative of E. coli $\mathrm{K}-12$, was used as the recipient strain [17]. The transconjugants (TC) of the first round transfer were used as donor strains to perform a second round transfer experiment (TC obtained from Dc1, Dc2, and Dc3 were named Tc1, Tc2, and Tc3, respectively). E. coli $\mathrm{DH} 5 \alpha$, a nalidixic-acid (NA) resistant derivative of E. coli $\mathrm{K}-12$, was used as the recipient strain in the second round transfer experiment.

Two donor VRE strains V1300 (Df1) and V1355 (Df2) isolated from human feces at the University of Occupational and Environmental Health, Japan were used. Df1 and Df2 contain transmissible plasmids positive for vanA, the gene that confers resistance to VCM. These plasmids from Df1 and Df2 belong to untypeable incompatibility groups. Rifampicin-resistant E. faecalis FA2-2 (Rf) was used as the recipient strain [18].

\section{Antimicrobial susceptibility testing}

The antimicrobial susceptibilities to FPL (BIOVET, SaintHyacinthe, USA), reference substance and purified by HPLC, were determined by using agar dilution methods according to the recommendation of the Clinical and Laboratory Standards Institute (CLSI) [19]. The following ATCC strains were used as controls for susceptibility testing: Staphylococcus aureus ATCC29213, E. faecalis ATCC29212, E. coli ATCC25922, and Pseudomonas aeruginosa ATCC27853.

\section{Growth inhibition testing}

Each donor and recipient strain was grown overnight at $37^{\circ}$ $\mathrm{C}$ in $1 \mathrm{ml}$ of Tryptic Soy Broth (TSB) (Bacto ${ }^{\mathrm{TM}}$, New Jersey, USA). $50 \mu \mathrm{l}$ of the growth culture was added to $1 \mathrm{ml}$ of TSB containing FPL $(0,2,4,8,16,32$, or $64 \mu \mathrm{g} / \mathrm{ml}$ for E. coli and $0,0.016,0.031,0.063,0.125,0.250$, or 0.500 $\mu \mathrm{g} / \mathrm{ml}$ for E. faecalis) and incubated overnight at $37^{\circ} \mathrm{C} .0 .1$ $\mathrm{ml}$ of ten-fold serial dilutions of overnight culture were spread on Tryptic Soy Agar (TSA) $\left(\right.$ Bacto $^{\mathrm{TM}}$ ) plates containing CEZ $(16 \mu \mathrm{g} / \mathrm{ml})$ for E. coli donor strains, VCM (8 $\mu \mathrm{g} / \mathrm{ml}$ ) for E. faecalis donor strains, and RIF ( 25 or $50 \mu \mathrm{g} /$ $\mathrm{ml})$ for $E$. coli and $E$. faecalis recipient strains, respectively and incubated overnight at $37^{\circ} \mathrm{C}$ before colony counting. Statistical analysis was performed by analysis of one-way ANOVA with Tukey-Kramer test to assess growth inhibition testing.

\section{First round conjugative transfer with FPL}

The broth mating method was used to determine the inhibitory effect of FPL on conjugative transfer of E. coli [13, 20]. Briefly, the donor strain was grown overnight at $37^{\circ} \mathrm{C}$ in $1 \mathrm{ml}$ of TSB. $50 \mu \mathrm{l}$ of overnight culture was added to $1 \mathrm{ml}$ of TSB containing $0,2,4,8,16,32$, or $64 \mu \mathrm{g} / \mathrm{ml} \mathrm{FPL}$. The recipient strain was grown overnight at $37^{\circ} \mathrm{C}$ in $1 \mathrm{ml}$ of TSB. $0.1 \mathrm{ml}$ of the donor culture and $0.1 \mathrm{ml}$ of the recipient culture were added to $0.8 \mathrm{ml}$ of TSB containing $0,2,4,8$, 16,32 , or $64 \mu \mathrm{g} / \mathrm{ml} \mathrm{FPL}$. This mixture was incubated overnight at $37^{\circ} \mathrm{C} .0 .1 \mathrm{ml}$ of ten-fold serial dilutions of overnight culture were spread on TSA plates containing selective antibiotics (transconjugant-selective plates contained $16 \mu \mathrm{g} / \mathrm{ml} \mathrm{CEZ} \mathrm{and} 50 \mu \mathrm{g} / \mathrm{ml}$ RIF) and incubated overnight at $37^{\circ} \mathrm{C}$, then colonies were counted.

Because E. faecalis used in this study contained transmissible plasmids with molecular size less than $30 \mathrm{~kb}$ which were not able to transfer between donor and recipient strains 
using the broth mating method, the filter mating method was used $[14,20]$. Briefly, the donor strain was grown overnight at $37^{\circ} \mathrm{C}$ in $10 \mathrm{ml}$ of TSB. $1 \mathrm{ml}$ of overnight culture was added to $5 \mathrm{ml}$ of TSB containing $0,0.016$, $0.031,0.063,0.125,0.250$, or $0.500 \mu \mathrm{g} / \mathrm{ml}$ FPL. The recipient strain was grown overnight at $37^{\circ} \mathrm{C}$ in $20 \mathrm{ml}$ of TSB. $2.5 \mathrm{ml}$ of the donor culture and $2.5 \mathrm{ml}$ of the recipient culture were then mixed. In the filtration step, $5 \mathrm{ml}$ of mixture was collected on a membrane filter (ADVANTEC, Tokyo, Japan; pore size $0.22 \mu \mathrm{m}$ ). The filters were placed on TSA containing FPL (concentrations as described above) and incubated overnight at $37^{\circ} \mathrm{C}$. The filters were transferred to a centrifuge tube containing $0.5 \mathrm{ml}$ of sodium chloride solution, and washed 3 times. $0.1 \mathrm{ml}$ of ten-fold serial dilutions of this solution were spread on TSA plates containing selective antibiotics (transconjugant-selective plates contained $8 \mu \mathrm{g} / \mathrm{ml} \mathrm{VCM}$ and $25 \mu \mathrm{g} / \mathrm{ml} \mathrm{RIF}$ ) and incubated overnight at $37^{\circ} \mathrm{C}$, then colonies were counted.

Transfer of the plasmid in transconjugants (TC) was verified by PCR analysis and plasmid profiles [21]. DNA was extracted from transconjugants by using InstaGene ${ }^{\mathrm{TM}}$ Matrix (Bio-Rad Laboratories, California, USA), according to the manufacturer's instructions. The PCR analysis, which allows detection of $\beta$-lactamase genes and the vanA gene, was performed as described previously [22, 23]. The conjugation study was performed three times and the transfer frequency was calculated by the number of transconjugants $(\mathrm{cfu} / \mathrm{ml})$ per the number of donors $(\mathrm{cfu} / \mathrm{ml})$.

\section{Second round conjugative transfer with FPL}

Using the same method as the first round conjugative transfer experiment, the second round conjugative transfer experiment was performed to determine whether the inhibitory effect of FPL on transfer frequency changed depending on plasmid type. The transconjugants of the first round conjugative transfer experiment were used as the donor cells; transconjugants harboring plasmids of Dc1, $\mathrm{Dc} 2$, and Dc3 were renamed Tc1, Tc2, and Tc3, respectively. A nalidixic-acid (NA) resistant E. coli $\mathrm{DH} 5 \alpha$ was used as the recipient strain. The transconjugants were selected by $16 \mu \mathrm{g} / \mathrm{ml} \mathrm{CEZ} \mathrm{and} 32 \mu \mathrm{g} / \mathrm{ml}$ NA. As the plasmids of VRE belong to untypeable incompatibility groups, these were not tested.

\section{Plasmid curing experiment}

The plasmid curing of E. coli and E. faecalis donor strains was performed as described previously [24]. In brief, each donor strain was grown overnight at $37^{\circ} \mathrm{C}$ in $1 \mathrm{ml}$ of TSB. $50 \mu \mathrm{l}$ of the growth culture was added to $1 \mathrm{ml}$ of TSB containing FPL $(0,2,4,8,16,32$, or $64 \mu \mathrm{g} / \mathrm{ml}$ for E. coli and $0,0.016,0.031,0.063,0.125,0.250$, or $0.500 \mu \mathrm{g} / \mathrm{ml}$ for
E. faecalis) and $100 \mu \mathrm{g} / \mathrm{ml} \mathrm{EtBr}$ was used as positive control [25]. $0.1 \mathrm{ml}$ of ten-fold serial dilutions of overnight culture were spread on TSA plates and incubated overnight at $37^{\circ}$ C. The isolated colonies were then replica plated on TSA plates and TSA plates containing CEZ $(16 \mu \mathrm{g} / \mathrm{ml})$ for $E$. coli or VCM $(8 \mu \mathrm{g} / \mathrm{ml})$ for E. faecalis using the Replica-Plating Tool (Scienceware,Bel-Art Products, USA) and incubated overnight at $37^{\circ} \mathrm{C}$ before colony counting.

The colonies that failed to grow on TSA plates containing selective antibiotics were considered as putative cured isolates. The loss of plasmid in the cured isolates was confirmed by plasmid profile [21]. The percentage of curing efficiency was expressed as number of colonies with cured phenotype per all counted colonies on TSA plates. The experiments were repeated four times. To assess the relationship between curing efficiency and dose of FPL, single regression analysis was performed.

\section{Results}

\section{Antimicrobial susceptibility testing}

The minimum inhibitory concentrations (MICs) for FPL for all E. coli donor and recipient strains were $128 \mu \mathrm{g} / \mathrm{ml}$, and those for all E. faecalis donor and recipient strains were 1 $\mu \mathrm{g} / \mathrm{ml}$.

\section{Growth inhibition testing}

FPL treatment significantly inhibited all $E$. coli growth at 32 and $64 \mu \mathrm{g} / \mathrm{ml}$ (Table 1). Moreover, FPL significantly inhibited E. faecalis Df1 and Df2 growth at $0.125,0.25$, and $0.5 \mu \mathrm{g} / \mathrm{ml}$ and inhibited E. faecalis Rf growth at $0.5 \mu \mathrm{g} / \mathrm{ml}$ (Table 1).

\section{Inhibition of conjugation transfer}

Untreated control transfer frequencies (TC/donor) for $E$. coli donor stains Dc1, Dc2, and Dc3 were $2.3 \times 10^{-2}$, $3.4 \times 10^{-3}$, and $1.4 \times 10^{-1}$, respectively and that for $E$. faecalis donor stains Df1 and Df2 were $2.2 \times 10^{-5}$ and $1.6 \times 10^{-5}$, respectively. For all E. coli and E. faecalis strains, exposure to FPL significantly decreased the transfer frequency in a concentration-dependent manner (Fig. 1a, b). Approximately 1.4-3.0 fold reduction in transfer frequency was observed when $E$. coli was treated with $2 \mu \mathrm{g} / \mathrm{ml}$ FPL. Similarly, the plasmid transfer in E. faecalis was inhibited up to $7.2-10.7$ fold in the presence of $0.5 \mu \mathrm{g} / \mathrm{ml}$ FPL.

In the second round conjugative transfer experiment when exposed to $64 \mu \mathrm{g} / \mathrm{ml} \mathrm{FPL}$, the transfer frequency of Tc1 and Tc2 harboring Inc FIB and I1-I $\gamma$ type plasmids was decreased compared with control (Fig. 1c). In contrast, the 

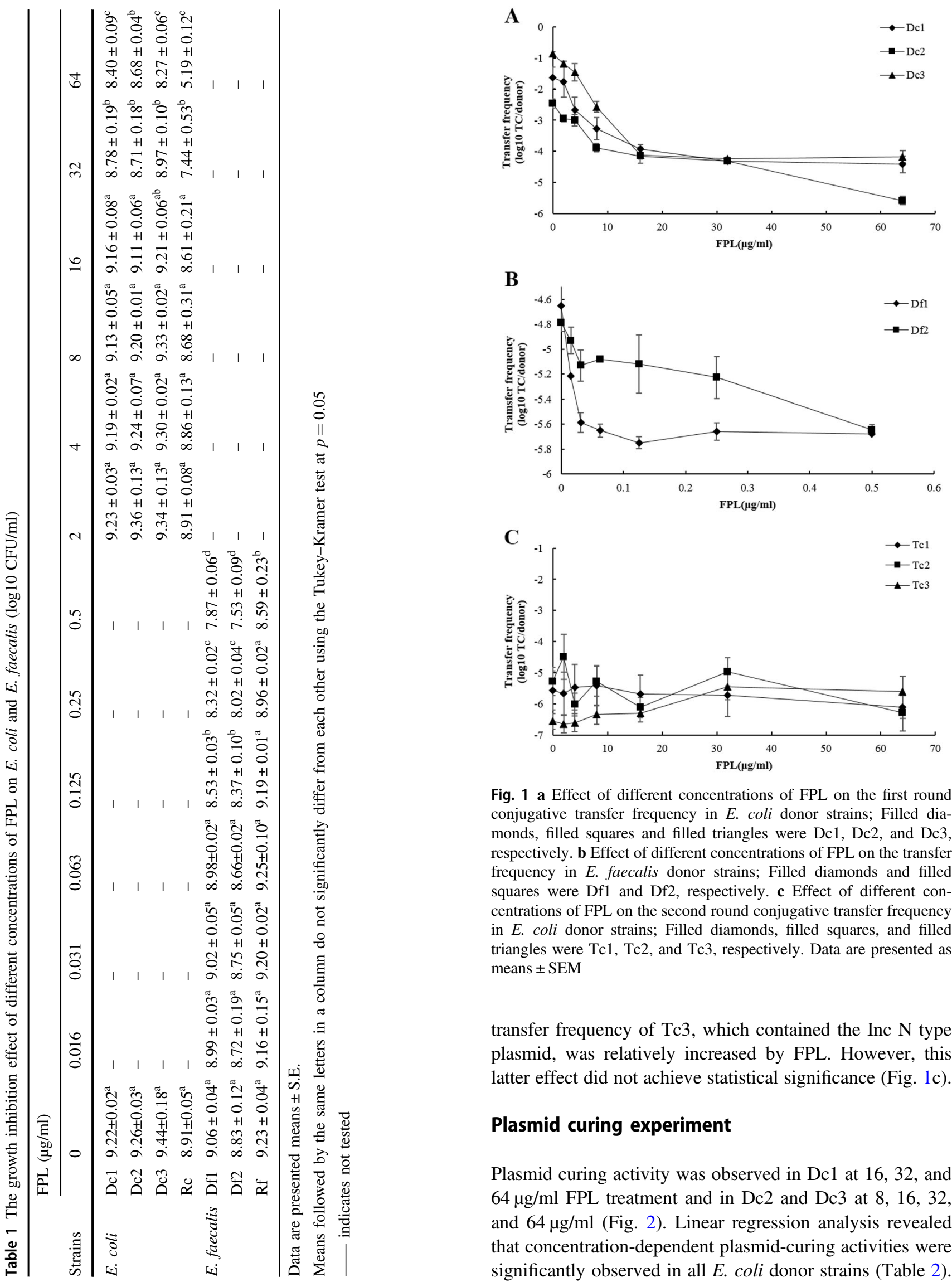

Fig. 1 a Effect of different concentrations of FPL on the first round conjugative transfer frequency in E. coli donor strains; Filled diamonds, filled squares and filled triangles were Dc1, Dc2, and Dc3, respectively. b Effect of different concentrations of FPL on the transfer frequency in E. faecalis donor strains; Filled diamonds and filled squares were Df1 and Df2, respectively. c Effect of different concentrations of FPL on the second round conjugative transfer frequency in E. coli donor strains; Filled diamonds, filled squares, and filled triangles were $\mathrm{Tc} 1, \mathrm{Tc} 2$, and $\mathrm{Tc} 3$, respectively. Data are presented as means \pm SEM

transfer frequency of $\mathrm{Tc} 3$, which contained the Inc $\mathrm{N}$ type plasmid, was relatively increased by FPL. However, this latter effect did not achieve statistical significance (Fig. 1c).

\section{Plasmid curing experiment}

Plasmid curing activity was observed in Dc1 at 16, 32, and $64 \mu \mathrm{g} / \mathrm{ml}$ FPL treatment and in Dc2 and Dc3 at 8, 16, 32, and $64 \mu \mathrm{g} / \mathrm{ml}$ (Fig. 2). Linear regression analysis revealed that concentration-dependent plasmid-curing activities were significantly observed in all E. coli donor strains (Table 2). 


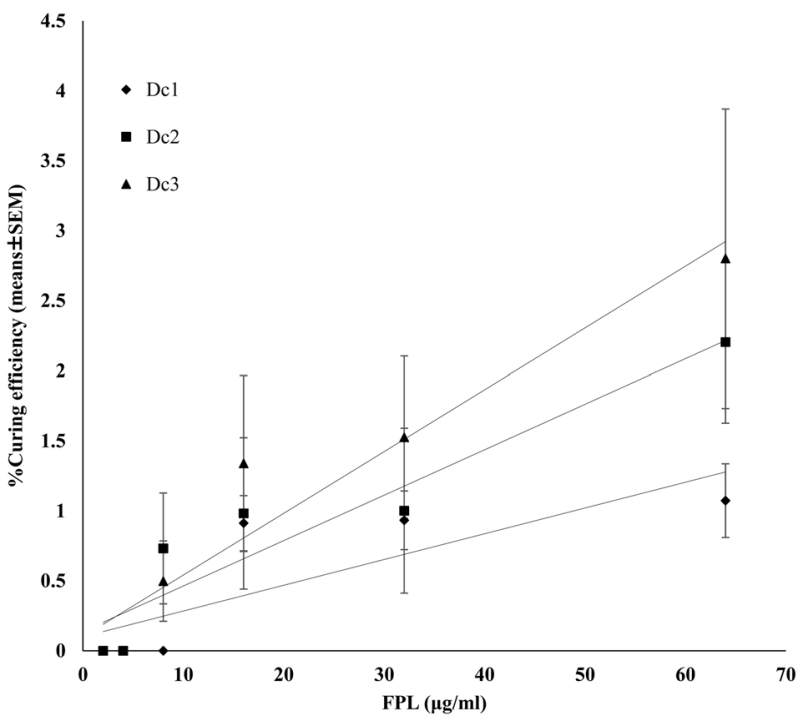

Fig. 2 Single linear regression analysis of the relationship between $\%$ curing efficiencies and different concentrations of FPL. Solid lines represent each linear line for dose-depend increased of curing efficiencies. Filled diamonds, filled squares, and filled triangles were Dc1, Dc2, and Dc3, respectively. Data are presented as means \pm SEM

Table 2 Regression valuables of curing efficiency and different concentrations of FPL treatment

\begin{tabular}{llll}
\hline Strains & Slope & $P$-value & $95 \%$ Confidence interval \\
\hline Dc1 & 0.02 & 0.0004334 & 0.0096 to 0.0273 \\
Dc2 & 0.03 & 0.0006043 & 0.0163 to 0.0486 \\
Dc3 & 0.04 & 0.0002412 & 0.0232 to 0.0650 \\
\hline
\end{tabular}

EtBr was able to cure plasmids successfully at $100 \mu \mathrm{g} / \mathrm{ml}$, and the curing efficiencies for Dc1, Dc2, and Dc3 were 1.3 $\pm 0.3 \%, 1.6 \pm 0.4 \%$, and $1.3 \pm 0.6 \%$, respectively. Plasmid curing activities of $64 \mu \mathrm{g} / \mathrm{ml}$ FPL against Dc1, Dc2, and Dc3 of E. coli were $1.1 \pm 0.3 \%, 2.2 \pm 0.6$, and $2.8 \pm 1.1 \%$, respectively, and were almost the same or relatively higher than those of $100 \mu \mathrm{g} / \mathrm{ml} \mathrm{EtBr}$. No plasmid curing activity was observed when $E$. coli was exposed to low concentrations of FPL ( 2 and $4 \mu \mathrm{g} / \mathrm{ml}$ ). Despite the fact that FPL induced plasmid curing in E. coli, no plasmid curing activity was induced in E. faecalis at any concentration (data not shown).

\section{Discussion}

In this study, the inhibitory effect of FPL on conjugative transfer was observed in a concentration-dependent manner for all ESBL-producing E. coli and VRE strains. Additionally, this reduction of transfer frequency was observed at lower concentrations than those used in the growth inhibition test. The conjugative pilus synthesized by the donor strain is essential for conjugative transfer in Gramnegative bacteria such as E. coli [26]. Unlike E. coli, Grampositive bacteria including $E$. faecalis do not use pili and the conjugation system is instead dependent on pheromoneinduced conjugation [27]. These results suggest that the inhibition mechanism in Gram-negative and positive bacteria by FPL is not dependent on the pilus.

Approximately, 1.4-3.0 fold reduction in transfer frequency was observed when E. coli harboring ESBL genes were treated with $2 \mu \mathrm{g} / \mathrm{ml} \mathrm{FPL} \mathrm{(the} \mathrm{transfer} \mathrm{frequencies} \mathrm{of}$ untreated controls were $-2.46 \sim-0.86_{\log 10} \mathrm{TC} /$ donor). In the previous study [13], exposure to $2 \mu \mathrm{g} / \mathrm{ml} \mathrm{FPL} \mathrm{com-}$ pletely inhibited the conjugative transfer of $E$. coli harboring antibiotic-resistance plasmids (untreated control transfer frequency was at $8.1 \times 10^{-4}$ ). The difference in transfer frequency between the previous reports and our results may be caused by strain differences or differences in the plasmids used in conjugation experiments. In fact, there was a significant difference even between the transfer frequencies of the three donor strains of $E$. coli when exposed to low concentrations of FPL in this study.

George et al. reported that the inhibitory effect of FPL on conjugative transfer depended on plasmid type [28]. However, in the first round transfer experiments, FPL significantly inhibited conjugative transfer of all plasmids belonging to distinct Inc groups. To confirm whether the inhibitory effects of FPL were really dependent on the type of plasmid, we performed a second round transfer experiment using the same type of donor strains (harboring the plasmids belonging to several Inc groups). We found that FPL decreased the transfer frequencies of Inc FIB and I1-I $\gamma$ type plasmids, but increased that of the Inc $\mathrm{N}$ type plasmid. However, untreated control transfer frequencies of the second round transfer experiment were significantly lower than those of the first round transfer experiment. These results suggest that FPL decreased or increased transfer frequency depending on plasmid type when transfer frequency was at low levels, whereas it indiscriminately reduced the conjugative transfer of all plasmid types when transfer frequency was high.

The plasmid transfer frequency in E. faecalis was inhibited up to $7.2-10.7$ fold in the presence of $0.5 \mu \mathrm{g} / \mathrm{ml}$ FPL, which is consistent with the previous study [14].

FPL is approved for use as a feed additive in broilers and pigs at $1-5 \mathrm{~g} /$ ton and $2-10 \mathrm{~g} / \mathrm{ton}$, respectively [29]. Although FPL may tend to be diluted or accumulated in gut depending on intestinal environment, most FPL is not absorbed in the gut and is excreted in feces [30]. Therefore residual FPL in the gut was considered to be the same as the approved concentration. For all E. coli and E. faecalis strains, inhibition of conjugational transfer was observed at $1-10 \mu \mathrm{g} / \mathrm{ml} \mathrm{FPL}$. However, approved concentrations of FPL are below the MIC level of E. coli $(128 \mu \mathrm{g} / \mathrm{ml})$ and above 
the MIC level of $E$. faecalis $(1 \mu \mathrm{g} / \mathrm{ml})$, suggesting that the above-approved concentration would have bactericidal actions for Gram-positive bacteria such as E. faecalis and sufficiently inhibit conjugative transfer of ESBL and vanA gene encoding plasmids. Resistance gene transfer is most likely to occur in feces [31] and FPL may act most effectively at preventing transfer in this medium. In fact, Bogaard et al. reported that FPL effectively suppressed the increase and dissemination of multi-resistant $E$. coli in the intestinal flora of pigs but increased FPL-resistant $E$. faecalis [32]. By contrast, there was no significant difference in the number of transconjugants between untreated control and FPL treated chickens [13].

FPL exhibited plasmid curing activity in E. coli harboring a plasmid carrying ESBL genes in a concentrationdependent manner significantly. The plasmid curing activities of a high concentration of FPL were almost the same as those of $\mathrm{EtBr}$, which is well known as a plasmid curing agent [25]. These results suggest that plasmid-curing likely contributes partially to the inhibition of conjugational transfer at high concentrations. By contrast, FPL had no plasmid-curing effect in E. faecalis. However, Keyhani et al. reported that no plasmid curing activity was observed when E. faecalis was exposed to either acridine orange or SDS, other known plasmid curing agents in E. coli [33], suggesting that species differences may explain this result.

In conclusion, our results suggest that the approved concentration of FPL for use as a feed additive in livestock animals would inhibit conjugational transfer of ESBL and $v a n A$ genes in the gut or in animal feces. The use of FPL as a feed additive may decrease the risk of dissemination of plasmid-mediated resistance genes from animal to human via the food chain.

Acknowledgements We thank Dr. Koichi Tanimoto (Laboratory of Bacterial Drug Resistance, Gunma University Graduate School of Medicine) for providing the E. faecalis recipient strain FA2-2.

\section{Compliance with ethical standards}

Conflict of interest The authors declare that they have no conflict of interest.

Open Access This article is licensed under a Creative Commons Attribution 4.0 International License, which permits use, sharing, adaptation, distribution and reproduction in any medium or format, as long as you give appropriate credit to the original author(s) and the source, provide a link to the Creative Commons license, and indicate if changes were made. The images or other third party material in this article are included in the article's Creative Commons license, unless indicated otherwise in a credit line to the material. If material is not included in the article's Creative Commons license and your intended use is not permitted by statutory regulation or exceeds the permitted use, you will need to obtain permission directly from the copyright holder. To view a copy of this license, visit http://creativecommons. org/licenses/by/4.0/.

\section{References}

1. Butaye P, Devriese LA, Haesebrouck F. Antimicrobial growth promoters used in animal feed: effects of less well known antibiotics on gram-positive bacteria. Clin Microbiol Rev. 2003; 16:175-88.

2. Landers TF, Cohen B, Wittum TE, Larson EL. A review of antibiotic use in food animals: perspective, policy, and potential. Public Health Rep. 2012;127:4-22.

3. Hall RM, Collis CM. Mobile gene cassettes and integrons: capture and spread of genes by site-specific recombination. Mol Microbiol. 1995;15:593-600.

4. Kojima A, et al. Extended-spectrum-beta-lactamase-producing Escherichia coli strains isolated from farm animals from 1999 to 2002: report from the Japanese Veterinary Antimicrobial Resistance Monitoring Program. Antimicrob Agents Chemother. 2005;49:533-3537.

5. Li X-Z, Mehrotra M, Ghimire S, Adewoye L. $\beta$-Lactam resistance and $\beta$-lactamases in bacteria of animal origin. Vet Microbiol. 2007;121:197-214.

6. Hornish RE, Kotarski SF. Cephalosporins in veterinary medicine ceftiofur use in food animals. Curr Top Med Chem. 2002;2:717-31.

7. Dolejska M, Villa L, Hasman H, Hansen L, Carattoli A. Characterization of IncN plasmids carrying blaCTX-M-1 and qnr genes in Escherichia coli and Salmonella from animals, the environment and humans. J Antimicrob Chemother. 2013;68:333-9.

8. Cetinkaya Y, Falk P, Mayhall CG. Vancomycin-resistant enterococci. Clin Microbiol Rev. 2000;13:686-707.

9. Cohen SH, et al. Clinical practice guidelines for Clostridium difficile infection in adults: 2010 update by the society for healthcare epidemiology of america (SHEA) and the infectious diseases society of America (IDSA). Infect Control Hosp Epidemiol. 2010;31:431-55.

10. Liu C, et al. Clinical practice guidelines by the Infectious Diseases Society of America for the treatment of methicillin-resistant Staphylococcus aureus infections in adults and children. Clin Infect Dis. 2011;52:18-55.

11. Tzavaras I, et al. Diversity of vanA-type vancomycin-resistant Enterococcus faecium isolated from broilers, poultry slaughterers and hospitalized humans in Greece. J Antimicrob Chemother. 2012;67:1811-8.

12. Barbara E, Murray MD. Vancomycin-resistant enterococcal infections. N Engl J Med. 2000;342:710-21.

13. Poole TL, et al. Effect of flavophospholipol on conjugation frequency between Escherichia coli donor and recipient pairs in vitro and in the chicken gastrointestinal tract. J Antimicrob Chemother. 2006;58:359-66.

14. Riedl S, Ohlsen K, Werner G, Witte W, Hacker J. Impact of flavophospholipol and vancomycin on conjugational transfer of vancomycin resistance plasmids. Antimicrob Agents Chemother. 2000;44:3189-92.

15. Sato $\mathrm{T}$, et al. Association of veterinary third-generation cephalosporin use with the risk of emergence of extended-spectrumcephalosporin resistance in Escherichia coli from dairy cattle in Japan. PLoS ONE. 2014;9:e96101.

16. Usui $\mathrm{M}$, et al. The role of flies in spreading the extended-spectrum $\beta$-lactamase gene from cattle. Microb Drug Resist. 2013;19:415-20.

17. Komatsu M, Aihara M, Shimakawa K, Yamanaka T, Matsuo S. Detection of extended spectrum beta-lactamases producing Enterobacteriaceae in feces. J J A Inf D. 2000;74:250-8.

18. Ike $\mathrm{Y}$, Tanimoto $\mathrm{K}$, Tomita $\mathrm{H}$, Takeuchi $\mathrm{K}$, Fujimoto $\mathrm{S}$. Efficient transfer of the pheromone-independent Enterococcus faecium plasmid pMG1 $\left(\mathrm{Gm}^{\mathrm{r}}\right)$ (65.1 Kilobases) to Enterococcus strains during broth mating. J Bacteriol. 1998;180:4886-92. 
19. Clinical and Laboratory Standards Institute: Performance standards for antimicrobial disk and dilution susceptibility tests for bacteria isolated from animals; approved standard-third edition. CLSI document 2008, M31-A3. CLSI, Wayne PA.

20. Clewell DB, An FY, White BA, Gawron-Burke C. Streptococcus faecalis sex pheromone (cAM373) also produced by Staphylococcus aureus and identification of a conjugative transposon (Tn918). J Bacteriol. 1985;162:1212-20.

21. Kado CI, Liu ST. Rapid procedure for detection and isolation of large and small plasmids. J Bacteriol. 1981;145:1365-73.

22. Saladin $M$, et al. Diversity of CTX-M $\beta$-lactamases and their promoter regions from Enterobacteriaceae isolated in three Parisian hospitals. FEMS Microbiol Lett. 2002;209:161-8.

23. Kariyama R, Mitsuhata R, Chow JW, Clewell DB, Kumon H. Simple and reliable multiplex PCR assay for surveillance isolates of vancomycin-resistant enterococci. J Clin Microbiol. 2000;38:3092-5.

24. Shriram V, et al. A potential plasmid-curing agent, 8-epidiosbulbin E acetate, from Dioscorea bulbifera L. against multidrug-resistant bacteria. Int J Antimicrob Agents. 2008;32:405-10.

25. Spengler G, et al. The mechanism of plasmid curing in bacteria. Curr Drug Targets. 2006;7:823-41.

26. Lawley T, Frost L, Wilkins B. Bacterial conjugation in gramnegative bacteria. Plasmid Biology.. Washington, DC: ASM Press; 2004. p. 203-26.
27. Andrup L, Andersen K. A comparison of the kinetics of plasmid transfer in the conjugation systems encoded by the F plasmid from Escherichia coli and plasmid pCF10 from Enterococcus faecalis. Microbiology. 1999;145:2001-9.

28. George BA, Fagerberg DJ. Effect of bambermycins, in vitro, on plasmid-mediated antimicrobial resistance. Am $\mathrm{J}$ Vet Res. 1984;45:2336-41.

29. Regulatory Frameworks to ensure Feeds Safety in Japan. 1976. Ministerial Ordinance on the Specifications and Standards of Feeds and Feed Additives. Available at www.famic.go.jp/ffis/ feed/obj/shore_eng.pdf

30. Ostash B, Walker S. Moenomycin family antibiotics: chemical synthesis, biosynthesis, biological activity. Nat Prod Rep. 2010;27:1594-617.

31. Huddleston JR. Horizontal gene transfer in the human gastrointestinal tract: potential spread of antibiotic resistance genes. Infect Drug Resist. 2014;7:167-76.

32. van den Bogaard AE, Hazen M, Hoyer M, Oostenbach P, Stobberingh EE. Effects of flavophospholipol on resistance in fecal Escherichia coli and enterococci of fattening pigs. Antimicrob Agents Chemother. 2002;46:110-8.

33. Keyhani J, Keyhani E, Attar F, Haddadi A. Sensitivity to detergents and plasmid curing in Enterococcus faecalis. J Ind Microbiol Biotechnol. 2006;33:238-42. 